\title{
润物细无声
}

“功能高分子材料”课程思政建设的探索与实践

宫琛亮 ${ }^{*}$, 张树江，张向东，惠新平 ${ }^{*}$

兰州大学化学化工学院, 兰州 730000

摘要: “功能高分子材料” 课程是化学专业的一门选修课, 也是功能材料专业的重要专业课之一。将思政元素多元 化引入课程教学中, 分别从思政元素与讲授内容的结合、引导学生对相关学科前沿的讨论和总结撰写综述论文并主 动参与科学研究三方面对 “功能高分子材料” 课程思政建设进行了探索和实践, 实现了 “润物细无声” 的课程思政 教学目标。

关键词: 课程思政; 功能高分子材料; 多元化

中图分类号: G64; O6

\section{Moistening Things Silently: The Exploration and Practice of Course Ideology and Politics Construction in "Functional Polymer Materials" Course}

\author{
Chenliang Gong *, Shujiang Zhang, Xiangdong Zhang, Xinping Hui * \\ College of Chemistry and Chemical Engineering, Lanzhou University, Lanzhou 730000, China.
}

\begin{abstract}
Functional polymer materials" is not only an elective course of the chemistry, but also an important professional course of the functional materials. In order to achieve the "moistening things silently" teaching goal, this paper introduces the exploration and practice of the course ideology and politics construction in "functional polymer materials" course from the following aspects: the combination of the ideological and political elements and teaching content, guiding students to discuss and interact with the frontier of related disciplines, and writing review papers and actively participating in scientific research.
\end{abstract}

Key Words: Course ideology and politics; Functional polymer materials; Diversification

为深入贯彻习近平总书记在学校思想政治理论课教师座谈会上的重要讲话精神, 2019 年 8 月, 中共中央办公厅、国务院办公厅印发了《关于深化新时代学校思想政治理论课改革创新的若干意见》, 明确提出要整体推进高校课程思政建设, 发挥所有课程的育人功能 ${ }^{[1]}$ 。2020 年 6 月, 教育部印发了 《高等学校课程思政建设指导纲要》, 要求全面推进高校课程思政建设, 明确了课程思政建设的总体 目标和重点内容, 为构建立德树人长效机制、实现全员全程全方位育人提出了具体指导意见和实施 方案 ${ }^{[2]}$ 。

作为理工科教育的重要组成部分, 化学专业的课程思政建设对于培养具有高尚道德品格、优秀

收稿: 2020-07-13; 录用: 2020-08-10; 网络发表: 2020-09-08

“通讯作者, Emails: gongchl@1zu.edu.cn (宫琛亮); huixp@1zu.edu.cn (惠新平)

基金资助: 兰州大学 2019 年 “课程思政” 示范课程建设项目 
科学素养的德才兼备化学专业人才、培养学生精益求精的大国工匠精神、激发学生科技报国的家国 情怀和使命担当具有重要意义。各高校对有机化学、无机化学、物理化学、分析化学、大学化学实 验等课程的课程思政建设进行了有益的探索和实践, 取得了良好的教学效果 ${ }^{[3-8]}$ 。功能高分子材料作 为高分子材料的一部分, 近年来对于人类科技发展进步起着重要的引领作用, 在化工、制药、医学、 环保、石油钻采与加工、建筑与装饰和光电信息等诸多领域得到了广泛应用。目前, 一大批功能高 分子材料已经实现了工业化生产, 形成了若干产业链, 而且在应用研究中不断涌现出创新性成果, 成 为科技发展的前沿领域之一 [9,10]。 “功能高分子材料” 课程主要介绍与功能高分子材料相关的基本知 识、基本概念及相关学科前沿研究的新概念、新进展, 是兰州大学化学专业高分子材料方向的一门 重要选修课, 也是高等学校战略性新兴产业对应本科专业一一功能材料的专业课之一。“功能高分子 材料” 课程的开设, 为学生了解学科前沿、理解聚合物太阳能电池、有机发光高分子材料等新兴领 域的相关知识和研究动态提供了良好的学习平台。也正因为如此, “功能高分子材料” 的课程思政建 设更利于将生产生活中的 “功能高分子” 元素和培养学生的科学精神、科学思维等思政元素有机结 合, 达到课程育人的教学目的。“功能高分子材料” 课程思政建设的目标是把马克思主义立场观点方 法的教育与科学精神培养相结合, 提高学生正确认识问题、分析问题和解决问题的能力; 注重科学 思维方法训练和科学伦理教育, 培养学生探索未知、追求真理、勇攀科学高峰的责任感和使命感; 培养学生的学习兴趣, 树立民族自豪感和使命感。课程涉及学科门类多、知识面广, 课程教学团队 从课程讲授、课堂讨论互动、课后综述论文撰写三个方面进行了探索和实践, 将思政元素多元化、 “润物细无声” 地融入教学中, 取得了理想的教学和育人效果。

\section{1 以教师为主导, 在课堂讲授中引入思政案例}

\section{1 将我国在功能材料领域取得的重要进展引入课程中, 增强学生的民族自豪感和社会使命感}

近年来, 我国在功能高分子材料领域取得了众多重要成果, 一些 “卡脖子” 材料得到自主研发 和生产, 一些研究成果达到了国际领先水平。在课程中, 教学团队通过调研, 总结代表性成果, 在 对应章节中进行介绍。表 1 列出了一些重要的科研成果、研究动态、时事动态与对应知识点、思政 元素结合的案例。例如, 在讲授高分子驻极体知识点时, 讲授新型冠状病毒疫情下的口罩生产和驻 极剂在口罩中的作用, 将 “驻极剂” 相对抽象的概念具体化、实物化。同时, 自然而然地将我国的 疫情应对措施和国外进行比较, 使学生切身感受到我国社会主义制度的优势和强大的社会治理能力。 在讲授电致发光高分子材料时, 原来只能介绍苹果、三星的 OLED 显示屏, 现在将华为折叠屏手机 作为 OLED 电致发光柔性屏进行介绍, 增强了学生的民族自豪感和爱国情怀。此外, 课程通过介绍 我国目前 “卡脖子” 的一些技术, 例如, 在讲授光刻胶时, 介绍目前我国光刻机、光刻胶技术现状, 并 以华为芯片供应遭美国制裁为例, 让学生认识到 “一定要把关键核心技术掌握在自己手里” 的重要 性, 提高学生的民族危机感和社会使命感, 鼓励学生为实现中华民族的伟大复兴而努力学习。

\section{表 1 “功能高分子材料” 课程思政元素举例}

\begin{tabular}{|c|c|c|c|}
\hline 事例 & 对应章节 & 对应知识点 & 思政元素 \\
\hline 功能高分子的发展历史及其在人类 & 第一章 绪论 & “功能高分子” 的概念、功能高分 & 科技进步对于人类发展的重要意义 \\
\hline 发展进步中的重要作用 & & 子的分类 & \\
\hline 西北师范大学雷自强教授科学治沙 & & 环境友好高分子在西北治沙中的 & 增强绿色发展理念, 树立扎根西部、建设西部的理 \\
\hline 成果介绍 & & 应用 & 念, 学习科学家高尚的道德情操和奉献精神 \\
\hline 兰州大学王为教授关于有机框架聚 & 第二章 功能 & 有机框架聚合物的制备方法 & 引导学生爱国爱校, 增强自豪感和荣誉感, 学习科 \\
\hline 合物的代表性成果 & 高分子的制备 & & 学家高尚的道德情操和奉献精神 \\
\hline 化学家王锦山博士在原子转移自由 & & 活性自由基聚合 & 中国科学家对于世界高分子发展的卓越贡献, 科学 \\
\hline 基聚合方面的研发事迹 & & & 研究对技术进步的推动作用 \\
\hline
\end{tabular}


(续表 1)

\begin{tabular}{|c|c|c|c|}
\hline 事例 & 对应章节 & 对应知识点 & 思政元素 \\
\hline 中国科学院新疆理化技术研究所 & 第三章 吸附与分离 & 多孔材料吸附原理、研究方法 & 增强绿色发展理念, 学习科学家铸而不舍的 \\
\hline 马鹏程研究员在吸油材料方面的 & 高分子 & & 科学精神, 学习科学家高尚的道德情操和奉 \\
\hline 代表性工作 & & & 献精神 \\
\hline 高分子保水剂的研究现状及前沿 & & 亲水性高分子的应用 & 绿色发展理念, 高分子学科与环境治理的紧 \\
\hline 介绍 & & & 密性, 培养学生的科研兴趣 \\
\hline 燃料电池工作机理及离子交换膜 & 第四章 高分子分离 & 离子交换膜在能源材料中的应用 & 增强绿色发展理念 \\
\hline 的介绍 & 膜与膜材料 & & \\
\hline \multirow[t]{2}{*}{ 纯生啤酒的膜过滤生产工艺 } & & 微滤、超滤、纳滤和反渗透膜 & 增强学生学习兴趣, 发现实际生产生活中的 \\
\hline & & & 科技元素 \\
\hline 口罩生产过程中驻极剂的作用、疫 & 第五章 电活性高分 & 高分子驻极体 & 理论联系实际, 社会主义制度的优势和治理 \\
\hline 情应对措施 & 子材料 & & 能力 \\
\hline \multirow[t]{2}{*}{ 华为折叠屏手机 } & & 有机电致发光材料(OLED, PLED) & 增强学生民族自豪感和爱国情怀, 传播实干 \\
\hline & & & 兴国理念 \\
\hline “蓝光之父”、诺贝尔物理学奖获 & & 电致发光材料 & 培养学生的科学精神 \\
\hline \multicolumn{4}{|l|}{ 得者中村修二的事迹 } \\
\hline 聚乙炔导电高分子的发现及 2010 & 第六章 导电高分子 & 聚乙炔本征型导电高分子材料 & 培养学生的科学精神和科学素养 \\
\hline 年三位诺贝尔化学奖获得者的事 & 材料 & & \\
\hline \multicolumn{4}{|l|}{ 迹 } \\
\hline Suzuki 偶联反应在光电材料中的应 & & 导电高分子材料的合成方法 & 基础研究与应用研究的紧密联系, 培养学 \\
\hline 用 & & & 生的科研兴趣 \\
\hline 曹镛院士、李永舫院士、侯剑辉研 & 第七章 光功能高分 & 聚合物太阳能电池 & 学习科学家的探索和创新精神, 培养学生 \\
\hline 究员团队关于有机太阳能电池的 & 子材料 & & 的科研兴趣 \\
\hline \multicolumn{4}{|l|}{ 代表性工作 } \\
\hline 光刻胶的研究现状、美国对华为芯 & & 光刻胶 & 树立学生的民族危机感, 明确历史担当和 \\
\hline 片的断供 & & & 责任, 传播实干兴国理念 \\
\hline 中科院化物所王晓龙研究员关于 & & 光固化树脂、3D 打印 & 通过学科前沿培养学生的创新意识和创 \\
\hline 3D 打印聚酰亚胺的代表性工作 & & & 新能力 \\
\hline 我国塑料的环境污染问题 & & 光降解高分子材料 & 增强绿色发展理念 \\
\hline 兰州大学王锐院士团队关于多肽 & 第八章 高分子试剂 & 多肽固相合成 & 学习科学家探索创新精神, 引导学生爱国 \\
\hline 药物的代表性工作 & & & 爱校 \\
\hline 绿色合成对于生态保护的重要性 & & 固定化酶 & 培养学生人与自然和谐共生意识, 明确人 \\
\hline & & & 类共同发展进步的历史担当 \\
\hline 复旦大学俞燕蕾教授关于液晶高 & 第九章 液晶高分子 & 液晶高分子的研究进展 & 培养学生的科研兴趣和创新能力 \\
\hline 分子的代表性成果 & 材料 & & \\
\hline 美国杜邦公司 Kevlar 纤维的结构 & & 液晶高分子的应用 & 树立学生的民族危机感和使命感, 了解生 \\
\hline 及性能 & & & 产工艺在高分子材料中的重要作用 \\
\hline 深圳大学人工皮肤的代表性成果 & 第十章 生物医用高 & 生物医用材料的应用 & 提升学生科研兴趣, 树立民族自豪感 \\
\hline 石河子大学贾釒教授在化肥缓释 & 分子材料 & 药物缓释材料 & 增强绿色发展理念, 培养学生发散性思维 \\
\hline 方面的重要工作 & & & \\
\hline
\end{tabular}




\section{2 将杰出科学家、科学发现轶事引入课程中, 把辩证唯物主义、历史唯物主义渗透到课程教学中, 培养学生的科学精神和科学素养}

任何重要的科研成果都是通过科学家艰苦努力, 从量变到质变的过程, 深入挖掘、提炼杰出科 学家的科研过程、重大科学发现背后的故事, 可以有效促进课程思政建设。在课程教学中, 我们将 重要科学成果的研发过程、科学家的励志故事与课程知识点有机结合(表 1)。例如, 在讲授导电高 分子时, 我们将 2010 年诺贝尔化学奖获得者 A. J. Heeger、A. G. MacDiarmid 和 H. Shirakawa 在发现 聚乙炔导电现象的故事介绍给学生。正是 H. Shirakawa 在聚乙炔制备中, 偶然得到了具有金属光泽 的聚乙炔, 通过导电性能测试发现了聚合物导电这一创新性研究成果。随后, 为了探究导电机理, 他又和另外两位科学家合作, 最终提出了聚乙炔导电的机理, 推动了导电高分子的飞速发展。通过 实例让学生感受到偶然中的必然因素, 理解良好的科学素养、团队合作精神对于科学研究的重要性。

又如, 在发光材料的讲授中, 举例 “蓝光之父”、日本科学家 S. Nakamura 在遭受白眼、科研条件受 限的条件下, 仍然坚持自我、甘坐冷板発数十年, 终于研发出高亮度蓝光 LED, 最终得到了世界认 可。可见任何重要的科研成果都是科学家艰辛劳动的结晶, 任何质变都是日积月累、铸而不舍的量 变引起的。再如, 在电致发光材料部分, 结合最新科研进展, 介绍了 Suzuki 偶联反应在光电材料制 备中的重要应用, 将基础知识与科学前沿有机结合, 使学生深入理解基础研究与应用研究的紧密关 系, 培养学生良好的科学精神和科学素养。

\section{3 将学科前沿与课程教学相结合, 提高学生的学习兴趣, 培养创新意识和创新能力}

“双一流” 建设要求培养具有较强创新意识和创新能力的专业人才。在教学实践中, 团队在每 个章节都介绍了最新科研进展和研究动态(表 1)。例如, 在讲授聚合物太阳能电池时, 介绍了华南理 工大学曹镛院士、中国科学院化学研究所李永舫院士、侯剑辉研究员团队等的最新科研成果和创造 的太阳能电池效率的世界纪录。通过介绍前沿科研成果和我国科学家的杰出工作, 培养了学生的科 研兴趣。在讲授光致变色时, 介绍了复旦大学俞燕蕾教授的工作, 并对偶氮类光致形变、光致变色 机理进行介绍, 使学生在理解知识的同时, 发现所学内容在最新科学研究中具有广泛应用。又如, 在讲授功能高分子制备方法时, 介绍了兰州大学王为教授团队发表于 Science 上的首次合成共价有 机框架材料大尺寸单晶的工作, 让学生了解学科前沿的同时, 更深理解母校坚守奋斗的优良传统, 引导学生爱国爱校。在讲授多肽合成时, 强调高分子试剂对于多肽合成的里程碑式作用, 介绍了兰 州大学王锐院士团队的多肽合成工作, 让学生充分走进学科前沿。在光固化树脂部分, 介绍了中国 科学院兰州化学物理研究所王晓龙研究员关于 3D 打印聚酰亚胺的代表性工作, 通过和学生交流, 加深学生对于光固化高分子材料的深入认识。通过将学科前沿和科学家的案例介绍给学生, 明显增 强了学生的科研兴趣。

\section{4 将绿色发展理念与课程有机结合, 增强人与自然和谐理念}

习近平总书记在 2019 年中国北京世界园艺博览会开幕式的重要讲话中提出, 只有 “追求人与自 然和谐” “追求绿色发展繁荣” “追求热爱自然情怀” “追求科学治理精神” “追求携手合作应对”, 才 能使绿色发展的理念深入人心、全球生态文明之路行稳致远 ${ }^{[11]}$ 。兰州大学地处祖国西部, 生态文明 建设的必要性和迫切性感同身受。我们将绿色发展理念贯穿于教学中, 使学生深切体会绿色发展的 重要性, 并将如何绿色发展通过对应知识点的具体实例进行介绍(表 1)。例如, 在讲授高分子膜时, 通过介绍燃料电池工作原理和离子交换膜的研究进展, 使学生深入理解绿色能源与高分子材料的紧 密联系。在高分子试剂部分, 针对小分子催化剂易污染、成本高和安全性差的问题, 以高分子过氧 酸的制备和使用为例, 介绍我国化工行业面临的高污染、高能耗、高风险问题, 强调开发高分子催 化剂的必要性和优势, 以及发展生物材料、固定化酶催化剂的广阔前景。在讲授吸水高分子材料时, 介绍了吸水高分子材料在治沙、干旱地区农作物种植以及农药、化肥缓释方面的应用; 介绍了西北 师范大学雷自强教授在治沙方面兢兢业业、无私奉献的事迹; 介绍了石河子大学贾金教授在化肥缓 释方面的重要工作, 强调过量使用化肥对生态环境的污染问题; 介绍了中国科学院新疆理化技术研 
究所马鹏程研究员在吸油材料方面的工作, 指出吸油高分子在环境治理领域的重要作用。在讲解光 降解功能高分子时, 对学生展示塑料污染的严重性和治理的迫切性, 通过介绍高分子材料的降解原 理、种类及发展现状, 树立学生对环境治理的使命感和责任感, 增强人与自然和谐共生理念, 明确 人类共同发展进步的历史担当。

绿色发展和生态文明建设需要科技的引领, 生态环境的治理和改善要建立在先进的绿色发展理 念、科学技术的有力支撑基础之上。通过介绍绿色发展领域的最新科研成果, 可让学生明确科学技 术在生态环境治理和保护中的重要作用, 将绿色发展理念落实到个人的实际行动中。

\section{2 以学生为中心, 进行学科前沿课堂讨论, 激发学生学习兴趣}

课程思政的主体是学生, 唯有调动学生的积极性, 让学生主动参与并投入到课堂中, 才能达到 理想的教学效果。在功能高分子材料的课程思政建设中, 课程教学团队将近年来功能高分子材料领 域的前沿、热点领域进行总结归纳, 篮选了 30 余个具体方向(表 2), 让学生根据兴趣选择其中的方 向, 进行文献资料检索和总结, 在每周最后一节课留出 20 分钟, 10 分钟学生进行介绍, 10 分钟教 师点评并引导学生进行讨论。在讨论中, 有意识引导学生将课堂知识和学科前沿结合, 培养学生的 创新思维, 激发学生的学习兴趣。同时, 在讨论中有意识地将我国相关领域的研究进展、“卡脖子” 的一些相关技术、国家对于自主创新的相关政策和战略进行介绍, 让学生从内心深处理解习近平总 书记所讲的 “一定要把关键核心技术掌握在自己手里” 的重要性。例如, 在学生讲到聚酰亚胺柔性 屏幕时, 介绍我国在聚酰亚胺领域的最新研究进展和技术瓶颈, 国家对于促进集成电路产业的相关 政策, 鼓励学生为实现中华民族的伟大复兴做出自己的贡献。通过学生汇报和自由讨论, 学生的学 习兴趣明显增强。有些学生通过对自己感兴趣的研究方向的深入了解, 明确了将来研究生深造的方 向, 对学生的职业生涯规划起到了积极的引导作用。

表 2 “功能高分子材料” 课程学生完成综述题目举例

\begin{tabular}{|c|c|c|}
\hline & 对应章节 & 综述题目 \\
\hline 第二章 J & 功能高分子的制备 & 原子转移自由基聚合的研究进展; 共价有机框架聚合物的研究进展; 超分子材料的研究进展 \\
\hline 第三章 & 吸附与分离高分子 & 高分子在缓释肥料中的应用; 高分子在油水分离中的应用; 高分子吸水剂 \\
\hline 第四章 & 高分子分离膜与膜材料 & 燃料电池电解质膜; 气体分离膜材料的研究进展; 高分子分离膜在海水淡化中的应用 \\
\hline 第五章 | & 电活性高分子材料 & 聚合物在超级电容器中的应用; 聚酰亚胺在电子柔性屏幕中的应用; 电致变色聚合物的研究进展 \\
\hline 第六章 & 导电高分子材料 & 高分子热电材料研究进展; 本征型导电高分子的合成方法; 聚合物电致发光材料的研究进展 \\
\hline 第七章 & 光功能高分子材料 & 柔性聚合物太阳能电池研究进展; 高分子非线性光学材料; 光刻胶 \\
\hline 第八章 & 高分子试剂 & 光固化树脂在 3D 打印中的应用; 固定化酶技术研究进展; 高分子催化剂研究进展; 多肽药物的研究进展 \\
\hline 第九章 & 液晶高分子材料 & 高分子液晶显示材料; 防弹高分子材料的研究和应用; 液晶高分子变色材料的研究进展 \\
\hline 第十章 & 生物医用高分子材料 & 高分子人工组织器官; 高分子在靶向治疗药物中的应用 \\
\hline 其他 & & 阻燃高分子材料研究进展; 形状记忆高分子材料; 自修复高分子材料研究进展 \\
\hline
\end{tabular}

\section{3 以产出为导向, 指导学生撰写综述论文, 主动参与 “大学生创新创业行动计划项目”}

课程思政的建设效果需要以学生的学习成果产出为衡量标准。在课堂讲授、指导学生进行相关 学科前沿讨论后, 教学团队要求学生在讨论的基础上, 结合教师的意见和建议, 利用课余时间进一 步完善资料、进行总结, 完成所选方向的综述论文撰写(表 2)。通过指导学生完成论文撰写, 学生的 文献检索、阅读理解、论文写作能力得到了明显提高, 科研兴趣和科研素养得到有效提升。2019 年 春季学期选修课程的学生全部申请了国家级和校级 “大学生创新创业行动计划项目”, 18 名学生主 动进入导师实验室开展科研训练, 学生的创新意识和创新能力得到了明显的锻炼和提高。 


\section{4 结语}

“功能高分子材料” 课程教学团队通过深入挖掘课程中的思政元素, 充分利用课程的专业性和 学术性, 通过学科前沿介绍、学术理论剖析、研究动态跟踪、科学家励志故事分享、课堂讨论、学 科前沿综述撰写等形式, 明显提升了学生的学习兴趣, 实现了循循善诱、润物细无声的课程思政教 育, 有效增强了学生的民族自豪感、社会使命感和绿色发展理念, 培养了学生的科学素养、创新意 识和创新能力, 取得了理想的教学效果和育人功能。

\section{参 考 文 献}

[1] 中共中央国务院关于深化新时代学校思想政治理论课改革创新的若干意见. [2020-06-18].

http://www.gov.cn/zhengce/2019-08/14/content_5421252.htm

[2] 高等学校课程思政建设指导纲要. [2020-06-18]. http://www.moe.gov.cn/srcsite/A08/s7056/202006/t20200603_462437.html

[3] 解从霞, 李光九, 耿延玲, 王小燕. 大学化学, 2019, 34 (11), 38 .

[4] 韩国志, 刘睿, 关建宁. 大学化学, 2019, 34 (11), 56.

[5] 王旭珍, 王新平, 王新葵, 田福平, 田东旭, 陈冰冰. 大学化学, 2019, 34 (11), 77.

[6] 刘刚, 张恒, 马荣, 宋其圣, 苑世领, 孙国翠. 大学化学, 2020, 35 (7), 53.

[7] 吕家根, 张成孝, 杜建修, 漆红兰, 高强, 岳宣峰, 张静, 刘伟, 汤薇, 段新瑞, 刘成辉. 大学化学, 2021, 36 (3), 1912002.

[8] 潘鹤林, 黄婕, 吴艳阳, 刘玉兰, 朱忆天. 大学化学, 2019, 34 (11), 113.

[9] 焦剑, 姚军燕. 功能高分子材料. 第2版. 北京: 化学工业出版社, 2016.

[10] 赵文元, 王亦军. 功能高分子材料. 第2版. 北京: 化学工业出版社, 2013.

[11] 习近平. 共谋绿色生活, 共建美丽家园一一在二 $O$ 一九年中国北京世界园艺博览会开幕式上的讲话. [2020-06-18]. http://env.people.com.cn/n1/2019/0429/c1010-31056269.html 